\title{
'Pure water' in Niamey, Niger: the backstory of sachet water in a landscape of waste
}

\author{
Sara Beth Keough and Scott M. Youngstedt
}

\begin{abstract}
Introduction
Clusters of waste dominated by plastic products are found alongside most neighbourhood streets in Niamey, Niger. This problem is not unique to Niamey. It is common throughout cities in poor countries that lack consistent, organized rubbish collection. A closer look at discarded products reveals much about the people who discarded them, as well as the connections that exist between neighbourhoods in Niamey and the larger, global economy. However, this landscape of waste has an intricate and complex backstory that is not necessarily apparent in the piles of rejected plastic on the roadside.

This article seeks to uncover the backstory of one element found in many landscapes of waste in Niamey: discarded half-litre plastic bags - called 'sachets' by Stoler et al. (2012) - that once contained cold water. This water is referred to primarily as 'piya wata' ('pure water') by residents of Niamey, a name whose origins are explored later in this article. Discarded bags are the final product of commodity and value chains of water production, exchange and consumption that fall mostly outside government-regulated water services. By working backwards from the discarded bags, through those who produce, refrigerate and sell them, to those who consumed the water in them and discarded them, we demonstrate that four key characteristics, mainly linked to commodity production, affect the economic value of sachet water: the label, the temperature of the water, the time of year the bag is sold, and the apparent 'purity' of the water. All of these are influenced by the social context in which they take place. We explore these elements of economic value alongside cultural context and social relationships to uncover a complex political economy of water selling with implications for the environment, poverty and socio-economic status, gender, local economies and global trade. ${ }^{1}$
\end{abstract}

\footnotetext{
Sara Beth Keough is Professor of Geography at Saginaw Valley State University. Her research focuses on material culture, media, cultural identity, migration and human-environment interactions in West Africa and Canada. She is the editor of Material Culture. Email: sbkeough@ svsu.edu

Scott M. Youngstedt is Professor of Anthropology at Saginaw Valley State University and has more than twenty-five years of field experience in Niger. He is the author of Surviving with Dignity: Hausa communities of Niamey, Niger (Lexington Books, 2013).

${ }^{1}$ In this article, we use the following currency conversion: 500 CFA francs $=$ US $\$ 1$. This reflects the average value of the CFA franc in 2015.
} 


\section{Commodity chains and value chains}

The material culture of plastic water bags cannot be understood without considering the social and cultural processes that create them (Bulchi 2002). Plastic water bags move through the commodity chain while individuals attach meaning and value to them. In this way, water bags have a rather fluid existence (ibid.) or 'social life' (Wagner 2013; see also Orlove and Caton 2010; Bridge and Smith 2003), not only in what the bags contain, but also as the bags and their contents pass through the phases of extraction, production, exchange and disposal. The material items themselves have economic and symbolic value, although that value changes as the bags move from large rolls of plastic sold in markets, to containers holding cold water, to things that are no longer needed once the water has been consumed. (The fact that the bags were commodities sold to people three times is just one part of the backstory, the commodity phase.) The stories surrounding these phases must be considered in any analysis (Page 2005). Thus, something that has been discarded, and is now part of what we call a landscape of waste, still has considerable value - though of a different sort - particularly in the way it communicates cultural values and practices, and is connected to larger stories and systems.

As plastic water bags move through the commodity chain, their value changes. The global value chain is as important as the global commodity chain in understanding the story behind the final, discarded bags in the landscape. Global value chains imply not just a connection between stages through which a commodity passes (and the actors involved), but also a connection between commodities, activities, social relationships and perceptions entailed in each link of that chain (Cook et al. 2004; Kaplinsky and Morris 2001; Ricketts et al. 2014; Tsing 2013; Zylberberg 2013). However, value is created and distributed unevenly throughout the commodity chain, resulting in changing power relationships between actors at each stage. For example, Swyngedouw (2004: 1) contends that value is added in the production stage. He argues that: 'In capitalist cities ... [the] circulation of water is also an integral part of the circulation of money and capital.' Water - and the objects used to extract, purify, transport, store and consume it - has passed through processes of commodification that add to its value. In contrast, Appadurai (1986: 13) challenges this Marxian account of value production by asserting that value is assigned during the process of exchange, which occurs within cultural, political and economic contexts. In her study of matsutake mushrooms, however, Tsing (2013) demonstrates how value is added both to the commodity itself and also to the process of acquiring it, at multiple phases in the commodity chain as the mushrooms are assigned different values by different actors as social relations are established and transformed. In other words, no one phase in the commodity chain is more important than others in assigning value.

Global commodity chains and value chains are a result of the movement of goods in the global economy. While many have benefited from globalization, sub-Saharan Africa's increased participation in the global economy has brought decreased income shares, especially for marginalized groups (Kaplinsky 2000). Thus, development efforts that focus on increasing the value in global value chains often emphasize the process of upgrading by increasing the efficiency of production, producing higher-value goods, or using new skills to expand into 
new economic sectors (Humphrey and Schmitz 2002). The process of upgrading takes many forms, but usually involves some type of empowerment through which 'marginalized individuals and groups are able to exercise a meaningful level of control over the progressive realization of their own well-being' (Macdonald 2007: 794).

Much of the research on commodity chains and value chains in sub-Saharan Africa focuses on case studies of cash crops and natural resource exploitation. Themes include the rise of buyer-driven global value chains (see, for example, Gibbon and Ponte 2005), increasing profits for smallholders by upgrading to high-value crops (see Zylberberg 2013), perceptions of risk in this process (see Ricketts et al. 2014), and the potential for poor countries to further integrate into, and benefit from, the global economy. Our study of sachet water is informed by these case studies, but is different from them in several ways. We return to these ideas later, but first we situate sachet water production in the broader historical context of water provision and privatization in Niamey, and then we focus on each link in the commodity and value chain, beginning with the discarded bag.

\section{Water privatization and the rise of sachet water in Niamey}

An important element in the backstory of sachet drinking water in Niamey is its emergence in the city's changing water regime at a time when urban water supplies across the globe were becoming complex and fragmented. In her book Privatizing Water, Karen Bakker (2010: 3-4) explains that 'the vast majority of formal private sector activity in water supply has taken place in urban areas, and the central promise made in the 1990s by proponents was that private companies would solve the world's urban water supply "crisis". She disaggregates the concept of privatization by explaining the various ways in which water is produced (industrial versus artisanal production, for example), the different entities that own and control water resources, and the means by which the management of water resources has become commercialized. Furthermore, she moves away from binary - public/private or formal/informal - descriptors used in reference to water ownership, production and management. Rather, Bakker promotes a hybrid perspective whereby both public and private entities are involved in providing water to the 'urban unconnected', as well as those with direct connections (Bakker 2010: 6). She introduces a tripartite typology to categorize water industry actors: governments, private corporations and community groups or individuals (ibid.: 26). While all three groups are involved in the story of sachet water in Niamey, it is this third group - one made up of individuals who are neither government employees nor members of private corporations, and one that serves the community, defines goals based on community needs, and considers community opinion - that is most prominent in our story.

The privatization of water in Niger is but one outcome of global corporatedriven neoliberal policies (such as structural adjustment) that have pushed for the privatization or shared management of utilities and services traditionally managed solely by the state, and have promoted the shrinking of government spending on and ownership of urban utilities and the fragmentation of state management. This process of privatization occurs in many forms and, in the case of 
sachet water, includes individuals working for themselves, in many cases producing the sealed water bags in the privacy of their own homes, and either selling water in public spaces or in private, locally owned shops. ${ }^{2}$ Like the urban water regime in Jakarta, sachet water is just one element in a complex 'scattered archipelago' of water access in Niamey (Kooy and Bakker 2014: 63).

Niamey's piped water services were entirely a public enterprise prior to 2001. Reforms in 2001, aimed at both increasing the urban water supply and establishing a financially sustainable water sector, resulted in a private-public partnership for water delivery (Bontianti et al. 2014: 285). Vivendi Water (now Veolia Water) purchased a 51 per cent share of the water utility in Niamey in 2001. A multinational corporation headquartered in France, Veolia Water is the world's largest supplier of water services. More than ten years later, Niamey's piped water service sector is self-supporting, but water access in poor neighbourhoods is still problematic (ibid.). ${ }^{3}$

Most residents of Niamey get water for their daily needs from the piped network in which water from the Niger River is chemically treated and then distributed through the city's pipe system. A few people who live on the periphery of the city own private wells. Access to the piped network for wealthy residents is direct, as water is piped into their homes. They can afford the high, up-front connection fees and minimum monthly payments, in addition to water use fees. This is why the piped network in Niamey has expanded into middle-class and wealthy neighbourhoods on the periphery and why it skips poor peripheral neighbourhoods, creating the archipelago - the water company is more likely to recover its initial investment in water infrastructure because incomes in these neighbourhoods are more stable, and residents will likely be able to regularly pay their monthly bills in the future. In neighbourhoods where income is more tenuous, a household may have its connection to the piped network blocked if its members cannot pay their bills, but the water company still has to cover the costs of maintaining infrastructure. For the majority in Niamey who are not directly connected to the piped network, and who thus obtain water from public water taps (standpipes), neighbours, or vendors who get water from public water taps and deliver it to households for a fee, access is fragmented, inconsistent, difficult and expensive. In fact, those with a direct connection pay less per litre of water than those who get water indirectly; in other words, water is cheaper for the wealthy than

\footnotetext{
${ }^{2}$ In 2017, we discovered two cases of large-scale commercial production of water sachets by corporations, one of which (Niger Lait) we were able to explore further through interviews and observations. These corporations, which would not reveal their water sources to us, chemically purify and oxidize the water before it enters the sachets. The sachets are only sold in bulk from the factory, for almost double the price of small-scale produced sachets, and most of the customers are wealthy Nigeriens and importers from Burkina Faso. We never saw sachets from these companies discarded on the roadside during our fieldwork, and we estimate that at least 98 per cent of the sachets produced in Niamey follow the commodity and value chains we describe in the following sections. Thus, large-scale commercial production of water sachets is not the focus of this article.

${ }^{3}$ Bakker (2010: 4) emphasizes that 'examples of well-run public and private water supply systems, as well as examples (sadly, more abundant) of poorly run public and private water supply systems can be found around the world. Accordingly, we cannot categorically refute private sector involvement in water supply, nor simplistically defend government provision.' Niamey's situation is particularly complex given its private-public partnership in water supply.
} 
TABLE 1

Cost of water in Niamey by transportation method

Transportation method

Piped water in home

Direct from public standpipe

Delivered to home from public standpipe

Sachet water (sold in half-litre bags)

Bottled water
Average cost per litre in CFA francs $(500$ CFA francs $=$ US $\$ 1$ in 2015)

$0.18^{*}$

0.60

1.4

50

500

Note: * From Bardasi and Wodon (2008). All other figures derived through the authors' research.

for the poor (Hungerford 2012; Keough and Youngstedt 2014; Youngstedt et al. 2016) (see Table 1).

When the piped system failed to provide residents with access to water, hybrid systems emerged, ones in which the division between private and public (and community) entities is blurred. In Niamey, vended water helps fill the gaps in water access, particularly in poor neighbourhoods. The sachet water economy is integrated into this inequitable system of water access. While pushcart vendors called ga'ruwa in Niamey - who deliver water to homes in twenty-litre containers have existed for decades (Youngstedt et al. 2016), sachet water sales are relatively new. Initially in the 1990s, sachet water producers and sellers manually filled small bags with water and hand-tied them. Today, however, much of the sachet water in Niamey is produced through a mechanized process: 'the latest low-cost technological incarnation of vended water' (Stoler et al. 2012: 3).

Because producing and vending sachet water spans government, private and community sectors, it is difficult to pinpoint exactly when it became part of Niamey's cultural landscape. In the absence of official records, we rely on our interviews with producers, vendors and customers in the summer of 2015. The practice of manually filling hand-tied plastic bags with water (still commonly used for selling ice) is older than the current mechanized process. Stoler et al. (2012), in their study of sachet water vending in Accra, Ghana, note the emergence of automated heat-sealing sachet machines in the late 1990s, all of which were imported from China. In Niamey, the automated system appeared more recently than in Ghana because the machines used in Niger were first imported from China to Nigeria, from where the concept and the technology spread to Niger. ${ }^{4}$ This diffusion explains why the most commonly used term in Niger for sachet water is the English phrase 'pure water', despite the fact that French is the official language. The term is pronounced as 'piya wata' - a 'Hausafication' of English. ${ }^{5}$

\footnotetext{
${ }^{4}$ Nigeria continues to import water-bagging machines from Chinese companies, but now also manufactures its own machines. Chinese companies include Dingli Packing Machinery and Zhangjagang Sanofi Machinery Co., Limited, while Nigerian companies include Global Sterling Products Limited and Business Cell Nigerian Limited. Sachet water machines are not manufactured in Niger.

'In Niamey, the Zarma term 'hari yano' is also regularly used for cold sachet water, whereas the 'pure' Hausa term for cold water, 'ruwan sanyi', is also used occasionally. Most words in Hausa end with vowel sounds. A couple of common examples of 'Hausafied' English words that have
} 
The most experienced water vendors that we interviewed indicated that they had been selling modern sachet water for between ten and thirteen years, although we must consider that the sachets themselves were initially imported from Nigeria into Niger before the automated technology arrived. In other words, we can say with confidence that modern, machine-sealed sachet water has been available in Niamey since the early 2000s, but it is difficult to determine exactly at what point residents of Niamey began producing the machine-sealed bags themselves. Furthermore, machine-sealed piya wata did not immediately supplant the handtied bags. For six to eight years they shared the market. Today, hand-tied bags of water are rare in Niamey. 'Pure water' sachets are now an integral part of a larger, complex landscape of water access and global trade in the city.

\section{The 'pure water' backstory: a commodity chain and value chain analysis}

We now construct the backstory of plastic water bags by moving from the discarded bags, through those who produce, refrigerate and sell them, to those who consumed the water in them and discarded them, and finally to the larger system of trade to which sachet water is connected. ${ }^{6}$ Because the production of sachet water is typically not visible from the street, we consulted 'gatekeepers' who knew where the water production was taking place. ${ }^{7}$ We knew that most of the activities in the sachet water economy occur in low-income neighbourhoods where water access is more tenuous, a condition also noted in Stoler et al.'s (2012) study: thirteen of the seventeen neighbourhoods included in this study are poor. We did, however, consider how the sale of sachet water plays out in wealthy neighbourhoods, and thus we included water vendors in three of these as well.

\section{Plastic water bags}

We observed discarded plastic water bags in most neighbourhoods in Niamey, wealthy and poor alike, indicating that the consumption of sachet water and the habit of discarding the bag immediately after consumption span the socioeconomic spectrum. The density of discarded bags, however, was greatest in poor neighbourhoods, because, unlike in wealthy ones such as Issa Beri, residents there cannot afford to pay private workers to regularly collect rubbish from roadsides and compounds. Because sachet water is the only form of packaged water

entered the vernacular in Francophone Niger are 'moto' for motorcycle and 'mota' for motor or automobile.

${ }^{6}$ In summer 2015, we conducted eighty interviews: ten with sachet water producers, sixty-one with sachet water vendors, and nine with consumers. We conducted most of the interviews in Hausa and a few in French. When participants spoke Zarma but neither Hausa nor French, we used a translator. We also draw from our collective fieldwork in Niger that spans more than twenty-five years.

${ }^{7}$ Our selection of neighbourhoods and vendors was not the result of random sampling, but rather a factor of the location and local knowledge of our gatekeepers. However, we were systematic in the selection of neighbourhoods for our interviews. These gatekeepers also introduced us to several sachet water vendors who, while much more visible, were unlikely to engage in conversation with two foreigners without some form of local mediation. For most of our interviews, except those with producers, we did not use gatekeepers. 
sold cold and on the street, it is usually consumed immediately upon purchase. Unlike plastic bottles, which are reused, there is little use for the empty sachet without an advanced recycling facility that is capable of transforming the bags into new commodities. In the face of inadequate solid waste collection, most people discard the bags wherever they happen to be after drinking their contents. The discarded bags ultimately clog gutters, sewers and drains, increasing exposure to raw sewage, animal waste and other toxins - a situation mirrored in Stoler et al.'s (2012) study of Accra. Those that are collected from wealthy neighbourhoods are deposited in empty areas of poor ones, or on the urban periphery. (Plastic grocery bags are collected from wealthy neighbourhoods and deposited in much the same way.) In addition, plastic bags are burned in trash heaps, causing air pollution. The environmental impact of discarded plastic bags and relocated rubbish was particularly evident during our fieldwork, which overlapped with the rainy season in southern Niger. Furthermore, since the storm sewers of Niamey empty into the Niger River, many bags end up in the city's water source, threatening fish and potentially clogging pipes that draw water into the city's water treatment facilities.

The clear plastic bags are printed with text indicating the reputed location of their production and other messages. We collected eight different brands of sachet water, and noted many others. Five indicated that they were made in Niger, and three in Nigeria. ${ }^{8}$ However, it is not clear that any of them were actually made in Niger - it is possible that all of the plastic is imported from Nigeria, and that it is later stamped in Niger. All five bags made in Niger include some English, including one that is entirely in English - 'Do Freedom Water'. Nigerien-made products rarely include English on their labels. The 'Do Freedom Water' sachet indicates that it was produced by 'Shehu Foods, Banizumbu, Niamy [sic]', with the spelling of 'Shehu' and 'Banizumbu' reflecting Anglophone Nigerian conventions. Francophone Nigeriens spell these names as 'Cheifou' and 'Banizoumbou'. This suggests that Nigerians are working in the water-producing business in Niamey, or at least that some Nigerians are producing the ink lettering that is stamped on plastic water bags. The 'D.A.I.B.A.' brand bag describes its contents in French, Hausa and English: 'Eau Filtree [sic]', 'Tatatchen Ruwan Sha' and 'Natural Water', respectively. Most brands made some claims about the quality of their product. The 'Nouveau Eghazar-Water, Eau de Table' brand manufactured by Ets. Abdel in Niamey claims that its water is: 'Traitement Fait Par Un System [sic]', 'Ultra Norderne [sic]', 'De Filtration Avancee [sic]', 'Mise en Sachet' and 'Entierement Securise [sic]' ('Machine Made', 'Ultra-modern', 'Advanced Filtration', 'Put in the Bag' and 'Entirely Secure'). Most brands include the words 'Manufacturing Date' and 'Best Before', but none had stamped dates. Most brands also include the words 'Dispose of Properly' and small images of a person dropping the bag in a rubbish bin. Adding a brand stamp to clear plastic bags adds value, as this process distinguishes contemporary sachets from the earlier, hand-tied ones. However, it is merely the presence of the label itself that adds value and communicates ideas of the water's 'purity', not the actual text of the label. In our research, there appeared to be no brand loyalty

\footnotetext{
${ }^{8}$ Niger-based companies included Eau Portable, Do Freedom Water, Mai-Deliliy, D.A.I.B.A. Eau Filtree [sic] and Nouveau Eghazar-Water. Nigeria-based companies included Top Honest Table Water, R.T.S. Table Water and Katanga Table Water.
} 
among customers. We return to this idea of branding when we discuss the role of consumers in the sachet water economy.

\section{Consumers}

People who purchase plastic bags of water do so to fulfil the desire to consume water that is cold and perceived to be clean, as the sachets are sold from coolers on pushcarts or directly from refrigerators in boutiques or small grocery shops. In other words, it is the cold temperature, the perception of purity created by clear water and a machine seal, and the label, all elements of production, that add value to sachet water for consumers. Consumers in Niamey are accustomed to purchasing all kinds of counterfeit or pirated products, including clothing, wristwatches, mobile phones, shoes, CDs and cassette tapes. As Stoller (2002: 95) points out, 'in the mass consumer market, difference in quality between the original and the copy is sometimes negligible'. Sachet water falls into the category of 'cheaply manufactured goods whose only allure is the fame of their trademark' (ibid.: 95). The trademark or label becomes more important than the quality of the item (Coombe 1996; Stoller 2002). However, in the case of piya wata in Niamey, any sachet label will do. As far as we can tell, consumers do not have brand loyalties. No one - not producers, not vendors, not consumers - mentioned loyalty to or preference for any particular brand. We never saw a consumer read the brand logo or lettering. All that seems to matter is that there is a brand stamp on the sachet and that it is cold.

The desire for cold water seems 'natural' in one of the world's hottest cities, but we maintain that this desire has only recently been created in Niger through the marketing and commodification of water. In traditional Hausa thought, it was seen as necessary to keep cold and heat in balance to ensure health, but 'the effects of heat (zafi) are felt mainly on the external body and are generally not as important in pathological explanations as are the effects of cold (sanyi)' (Wall 1988: 190). Cold produces dead blood, increased phlegm, colds, stomach ailments, rashes, arthritis, headaches, lethargy and infertility (ibid.: 187-90). The Songhay and the Zarma similarly recognize hot and cold illnesses (Olivier de Sardan 1982; Stoller and Olkes 1987). ${ }^{9}$ 'Cold illnesses - called yeni in Songhay - are associated with rheumatism, arthritis, upper respiratory infections, and other similar disorders.' ${ }^{10}$ Furthermore, there is a spirit dimension to coldness: cold spirits - called hargay in Songhay - are spirits of death and disorder. ${ }^{11}$ The Zarma, who, like the Hausa, have adopted the Songhay cold spirits (hargay), associate cold with the same ailments that Hausa do, except that they do not regard it as a cause of stomach ailments and infertility. ${ }^{12}$

In short, people living in Niamey hail from backgrounds where cold, including cold water, was viewed negatively. Were such feelings to persist or be pervasive in the present day, the marketability of sachet water would be restricted. The young,

\footnotetext{
${ }^{9}$ Also, personal correspondence with Brian Nowak, 2016; personal correspondence with Paul Stoller, 2016.

${ }^{10}$ Personal correspondence with Paul Stoller, 2016.

${ }^{11}$ Ibid.

${ }^{12}$ Personal correspondence with Brian Nowak, 2016.
} 
however, associate access to refrigerated consumer products with modernity - and the consumption of cold sachet water is largely restricted to those who are below forty years of age. Furthermore, many of them are more tolerant of cold drinks, having suffered less tooth decay than older people, many of whom have dental problems due to the popularity of highly sugared tea and coffee and the lack of effective oral hygiene practices.

The consumption of sachet water is typically associated with poverty and inadequate access to water (Stoler et al. 2012), but our research indicates that both poor and rich use the product, with different associations. A half-litre sachet of cold water sells for 25 CFA francs (approximately US\$0.05 in 2015) and is hence relatively affordable, but it still costs more than the same amount taken directly from public standpipes, which is the cheapest way for Niamey residents without a direct connection to the piped network to obtain treated water (see cost comparison in Table 1). Drawing on their survey data of 533 households in Niamey, Bardasi and Wodon (2008: 5) documented an inverse relation between water prices and class status: 'the highest price is paid by households in the bottom quintile; these households have also the lowest consumption level. The unit price steadily decreases with the accumulation of wealth while consumption increases.' Indeed, the poorest quintile of Niaméens paid an average of 2.6 times more per unit of water than the richest quintile, and the poorest quintile consumed on average one-quarter the amount of water that the richest quintile drank (Bardasi and Wodon 2008: 9). ${ }^{13}$ The people we interviewed saw the purchase and consumption of sachet water as a visible display of their poverty because this typically indicates that they lack access to refrigeration. As one participant explained: 'The only time I can drink cold water is when I buy piya wata because my family is too poor to own a refrigerator.' Another participant told us: 'When I drink piya wata, everyone knows I am poor.' 14

Sachet water was also consumed, with rather different connotations, in three wealthy neighbourhoods we observed (Dar es Salam, Issa Beri and Maurice Delens), where most households are connected to the electrical grid and the piped water network and have back-up generators. First, we noticed that sachet water is sold from boutiques in these neighbourhoods, implying a customer base for this product, hence our inclusion of them in this study. In one instance, attendees at a wedding (where large tents were erected on the street for the day) made multiple trips throughout the day to a nearby boutique to purchase sachet water. In another case, the host of a party bought sachet water in bulk (bags of twenty sachets sold at air temperature), kept it in a refrigerator at his home, and then served it to guests during the party. Finally, a man driving a relatively new Mercedes-Benz car pulled up to a boutique, bought a sachet of water, consumed it immediately, and then discarded the bag on the ground outside the boutique as he drove away.

\footnotetext{
${ }^{13}$ Access to private piped water also involves an initial payment for pipes to link the home to the municipal network and monthly meter rental fees. Swyngedouw (2004: 2) suggests 'that the power/ money/water nexus can be introduced as a conceptual triad, which lays bare the political economy of the urban fabric and the functioning of mechanisms of domination and subordination within the urban arena'.

${ }^{14}$ Purchasing cold water can also simply be due to being far from home due to work, socializing or shopping.
} 
In the consumption of sachet water by the wealthy, various symbolic and practical aspects are in evidence. A need to quench thirst and a desire for cold water are conditions shared by the wealthy and poor alike, but while poor consumers we interviewed felt that the act of consuming sachet water was a display of poverty, wealthier consumers tended to see sachet water and its accessibility in public areas as a convenience to which they are entitled. Furthermore, the discarding of bags by wealthy consumers in wealthy neighbourhoods can communicate their status as people who can afford rubbish collection, in contrast to poor consumers who simply have no other place to put the empty bags. Consumers pay the same price for sachet water across the city. The impact of that cost on the individual, however, is different depending on the socio-economic position of the consumer. Furthermore, the symbolic value of the sachet varies by consumer group.

\section{Vendors}

The consumers, who ultimately discard the plastic water bags and create the landscapes of waste, purchase those sachets in one of two primary ways: from mobile vendors who walk the streets selling the cold bags out of coolers on pushcarts or from buckets carried atop their heads (Figure 1), or from small roadside boutiques that sell the bags out of refrigerators (Figures 2 and 3). Interviews with both types of vendors further reveal the backstory of discarded plastic bags, and indicate considerable complexity in the economy of water vending. Vendors are an important link in the commodity chain between consumers and producers.

The most publicly visible vendors of sachet water in Niamey are the (constantly) mobile ones and those with roadside tables. ${ }^{15}$ Most of the mobile vendors work in poor neighbourhoods, and most are children or young people - as mobile water vending requires agility and physical labour, including hours of walking in typically hot temperatures - whereas the sedentary ones operating at tables are adults. Selling piya wata on foot is an entry-level job for local and recent migrant youth in Niamey. ${ }^{16}$ Five youths explained that they work long hours only during school vacations. Both types of vendors work long days: eight hours on average, six or seven days per week. When we asked mobile vendors why they sold water, three common answers emerged: they were instructed by family members, they were unable to find other work, or they preferred it to sitting around 'doing nothing' (zaman banza in Hausa).

\footnotetext{
${ }^{15}$ Vendors with roadside tables are also mobile in the sense that they store their tables in their homes during the evening and wheel them to their regular roadside spots during the day. These vendors are most commonly found along streets in poor neighbourhoods and major market areas. The three vendors selling sachet water at tables included a forty-year-old migrant Hausa woman from Dosso, Niger who had been selling piya wata in Niamey for ten years (and sold water in hand-tied plastic bags for ten years before that), a forty-year-old migrant Hausa man from Abuja, Nigeria who had been selling sachet water in Niamey for two years, and a thirtyyear-old migrant Zarma man from Baleyara, Niger who had been selling piya wata in Niamey for three years. Two of the three table vendors also sold juice in hand-tied bags, in addition to sachet water.

${ }^{16}$ Mobile vendors in our study ranged from eight to forty years old. Most are boys and men. Fifty per cent identified themselves as Hausa, and 50 per cent identified themselves as Zarma. They had been in business for as little as three days and for as long as nine years, and for an average of fourteen months.
} 


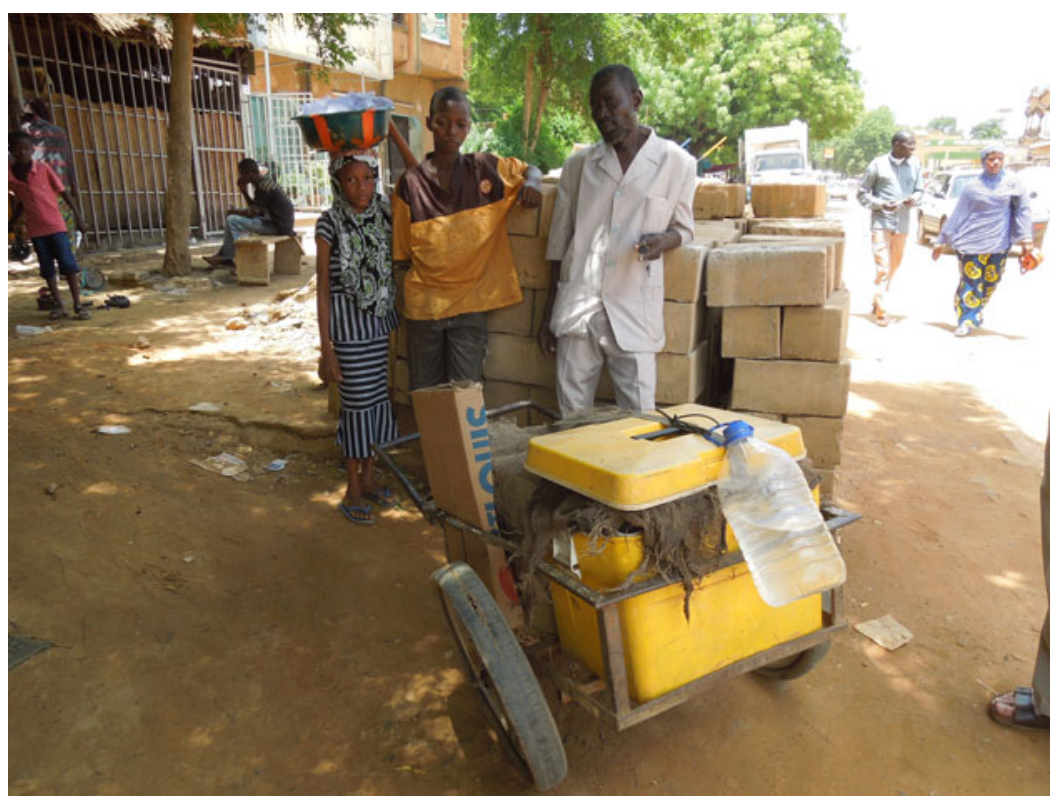

FIGURE 1 Mobile sachet water vendors, with a cooler containing bags on a pushcart in the foreground. The girl on the left has sachets in the bucket on her head.

The mobile vendors in our sample almost always worked for people who owned refrigerators. In contrast to the economy of home water delivery, which is entirely controlled by men (Keough and Youngstedt 2014; Youngstedt et al. 2016), women in Niamey have creatively - and virtually invisibly - inserted themselves into the commodity chain by purchasing sachets in bulk and refrigerators, and then sending their children out to sell the cold bags. Adult women, especially those who are married with children and extended families, cannot spend eight or more hours a day walking the streets to sell water. However, women who have acquired refrigerators, even small ones, can buy sachet water in bulk (200 CFA francs for a bag of twenty) and send their children out to sell it for 25 CFA francs per bag, yielding a gross profit of 300 CFA francs per bag of twenty and 1,830 CFA francs on average over the course of a day. ${ }^{17}$ Women's income is

\footnotetext{
${ }^{17}$ The 200 CFA franc figure is the average price that shop owners pay producers for a bag of twenty sachets. We did not ask children how much their mothers paid for bags of twenty, but we think it is probably similar. The bags of twenty sell for as little as 150 CFA francs each and for as much as 300 CFA francs each. In contrast, there is no variation in the price of individual half-litre sachets of piya wata: they are always 25 CFA francs each as long as they are cold. A few vendors sell warm sachet water for 15 CFA francs each. Although many of the mobile vendors we interviewed could not estimate the number of sachets they sold per day on average, those that could estimated that they sell as few as forty bags a day and as many as 350 bags per day, with an average of 122 water sachets sold daily. Thus, a woman whose child sells 122 bags of piya wata in a day earns 1,830 CFA francs or US\$3.66 in gross profits.
} 


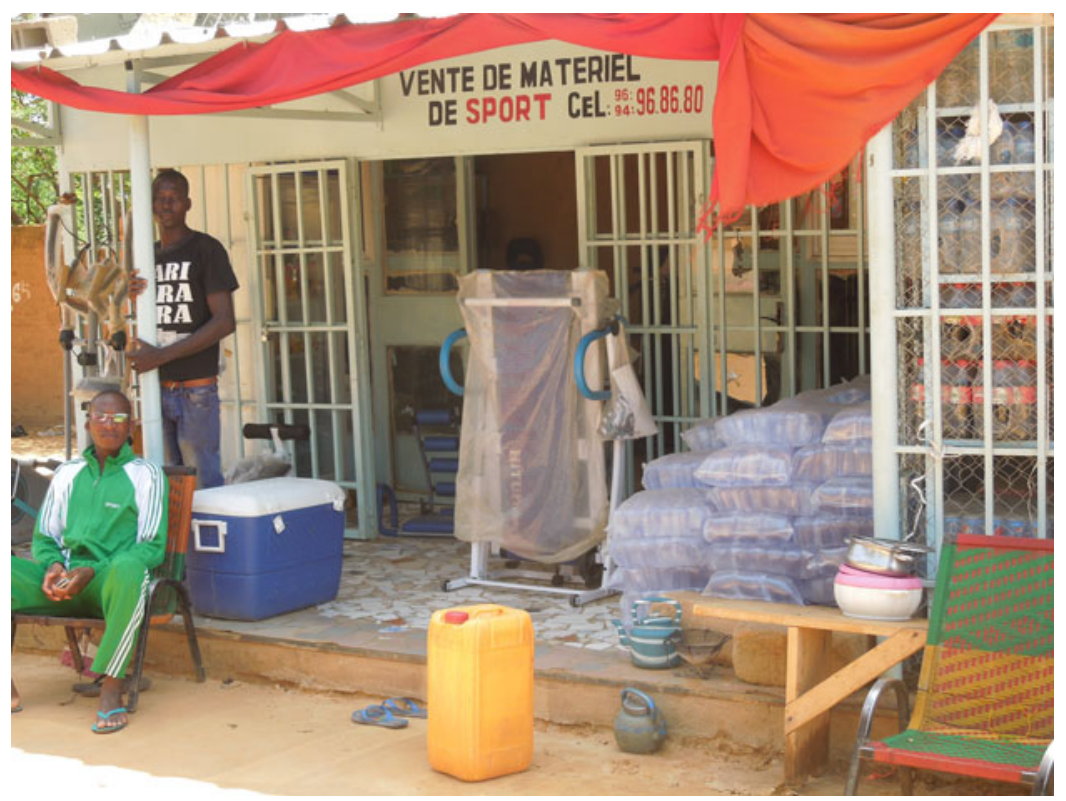

FIGURE 2 A boutique with sachet water in bulk on the patio.

offset by the costs of purchasing refrigerators (second-hand refrigerators are available for 25,000 CFA francs in Niamey), paying higher electricity bills, and paying children who are not their own to sell sachet water.

Although women are newcomers to the water economy of Niamey, their entrepreneurial strategy is based on older patterns. Many scholars (Callaway 1984; Hill 1969; Schildkrout 1982; Wall 1988) have documented a long history of women in the region - even secluded wives - operating successful businesses from their homes by sending their children into the streets and markets to sell their products, particularly cooked food and kola nuts. 'In Hausa society, any income that wives earn on their own is inalienably theirs' (Callaway 1984: 440), and women in Niamey need money more than ever to survive in the capitalist economy, to participate in the naming ceremonies and weddings of relatives and friends, and to integrate themselves in women's exchange networks (foyandi). In other words, women sell water indirectly and take advantage of the demand for water to support their families, an activity that, if done directly, would not be culturally acceptable.

Of the twenty mobile sellers we interviewed who worked for family members, only three were paid directly for their work: an average of 11,000 CFA francs per month. The others were paid in kind, with money from the sales used to buy them food or supplies and clothes for school or important Muslim holidays, or for transport. Those who worked for non-family members were paid an average of 8,000 CFA francs per month for their work.

There was consensus about the difficulty of the work. Several cited fatigue and 'heavy' legs due to pushing heavy carts on the uneven, sandy streets of Niamey. 


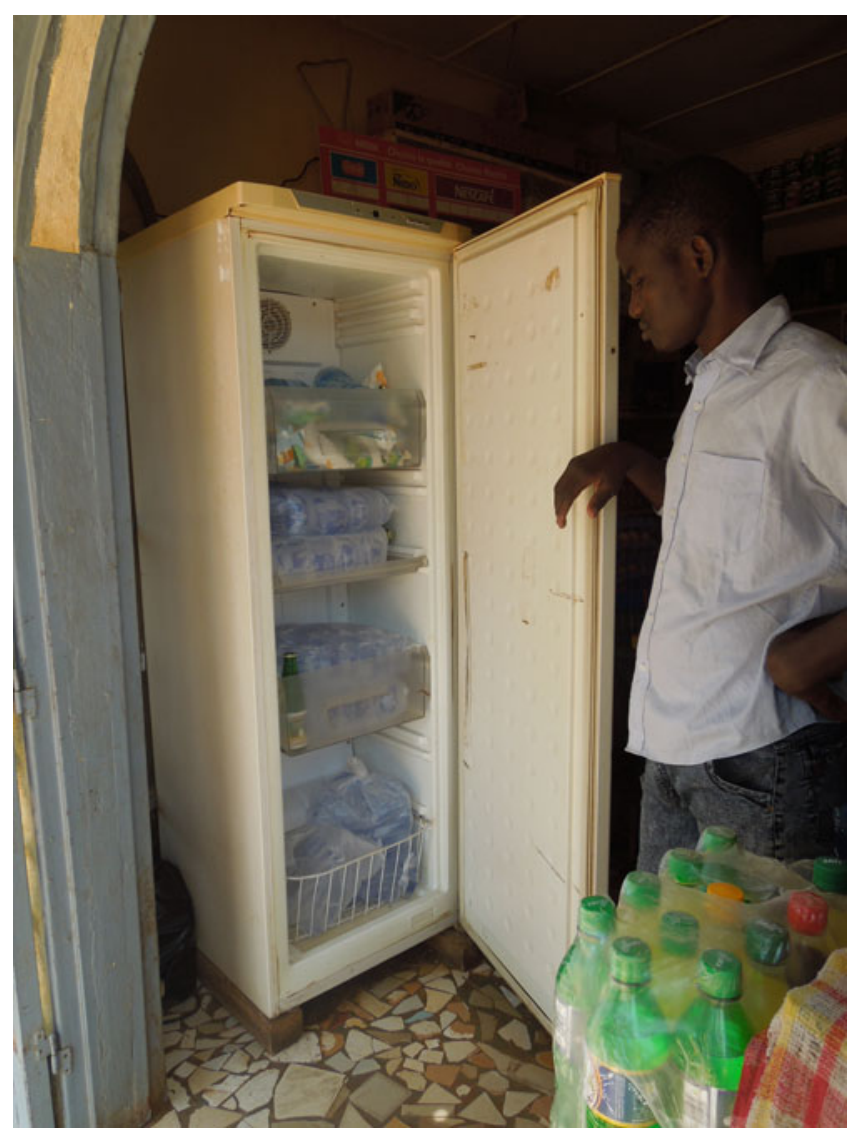

FIGURE 3 A boutiquier and his refrigerator filled with cold sachet water for sale.

Those who carry the sachets in bowls atop their heads explained that they suffer frequent headaches. Nevertheless, most mobile vendors maintained that they were proud to have been given the responsibility to work and handle money, to help support their families, and to contribute to their own needs.

The second group of sachet water vendors - boutiquiers - sell sachets from shops on the roadside, and thus are sedentary rather than mobile. All twentyseven boutique owners in our study were men, with an average age of thirty-six years. Most were Hausa, but Zarma, Songhay, Fulani and Arabs are also involved. Boutiquiers choose the products to sell in their shops, unlike children who sell sachet water on pushcarts because they are told to do so by their mothers. ${ }^{18}$ They say they sell sachet water because it is popular and many people buy it: a response that was universal across all boutiquiers in both

\footnotetext{
${ }^{18}$ The most common goods for sale in the boutiques of Niamey are canned tomatoes and fish, rice, cooking oil, powdered milk, tea, coffee, cigarettes, mobile phone cards and sachet water.
} 
wealthy and poor neighbourhoods. Boutiquiers purchase sachet water in bulk (bags of twenty sachets for an average of 200 CFA francs) from producers who deliver it regularly to the shops. Some then sell the bulk bags to the mobile vendors with carts. Most boutiques in wealthy neighbourhoods sell bottled water alongside the sachets, but boutiquiers noted that the latter is much more popular, enjoys higher consumer confidence, and sells faster. In poor neighbourhoods, boutiquiers purposefully carried no bottled water, stating that it was too expensive for their clientele (see Table 1 for a price comparison); one stated that 'rich clients buy bottled mineral water. Most of my clients buy piya wata.' Another explained: 'Everyone likes it. It is cheap. My clients are mostly poor people.'

As mentioned earlier, there was no brand loyalty among boutiquiers, and they did not mention any preference for labels. Rather, the loyalty lies between the boutiquiers and the sachet water producer. All boutiquiers told us that they buy sachet water in bulk from the same one or two producers, who regularly deliver the water to the shops.

Although neither mobile vendors nor boutiquiers were inclined to estimate the number of sachets they sell per day, some reported selling as few as seventy and as many as 400 sachets per day, with a daily average of 213 . Furthermore, responses revealed a significant difference between wealthy neighbourhoods, where boutiquiers estimated that they sold about 150 sachets per day, and poor ones, in which about 350 were sold. ${ }^{19}$ Whatever the neighbourhood, many more bags are reportedly sold per day during the hot season (three to four months) than at other times of the year. ${ }^{20}$ Sachets sold in boutiques are usually consumed immediately upon purchase and then discarded nearby, usually in front of or around the boutique itself. In fact, one of the ways in which we identified boutiques that sold sachets of water was by observing the density of the discarded bags outside the shops.

\section{Producers}

While cold water vending is common in both wealthy and poor neighbourhoods in Niamey, sachet water producers are almost exclusively located in poor neighbourhoods. Sachet water vendors in Niamey buy the sachets in bulk (as described above) from producers. For interview purposes, we divided these producers into two groups: small-scale and large-scale producers. We interviewed only one in the former category - a sixty-year-old semi-retired Hausa man living in Zongo - but he shared information about the experiences of other small-scale producers

\footnotetext{
${ }^{19}$ Sales volumes occur in an inverse relationship to refrigerator ownership. Among the twentyseven boutiquiers in the study, refrigerator ownership ranged from one to five, with an average ownership of two refrigerators each. Boutiquiers in wealthy neighbourhoods owned twice as many refrigerators on average as those operating in poor neighbourhoods -2.8 compared with 1.4. This disparity in sales can be explained at least in part by the fact that boutiquiers in poor neighbourhoods devote a much higher percentage of their refrigerator space to piya wata than boutiquiers in wealthy neighbourhoods do.

${ }^{20}$ Almost three-quarters of boutiquiers explained that their work is difficult, but their problems are relatively minor compared with those of the mobile vendors. Broken sachets and constantly getting up and down from their chairs to serve customers were the most commonly cited problems. Others mentioned slow sales during the cold season (three to four months), long work hours, and the constant need to sweep up discarded sachets.
} 
whom he knows. Small-scale producers buy rolls of plastic in the market. Then, using simple electric machines about the size of laptop computers that are imported from China and available in local markets for about 5,000 CFA francs, they create bags, fill them with water stored in their homes, and then manually seal them, often suffering repeated small but painful electric shocks from the crude machines. Since they produce only about one bag per minute, they cannot compete with large-scale producers. This method is even slower than the hand-tied method in which no machines are employed. The small-scale producer, in a practice he told us was common, buys pre-labelled piya wata sachets and fills them manually with water delivered to his home by ga'ruwa and stored in a clay pot. These sachets are indistinguishable from those that take water directly from the piped network, filter it, and pack it using automated machines. However, for reasons discussed earlier and to be further elaborated below, only a very small number of consumers purchase the cheaper, unlabelled, hand-tied bags of water that sell for $10 \mathrm{CFA}$ francs each. Most are willing to pay $25 \mathrm{CFA}$ francs each for sachets of labelled piya wata as they trust that this water is 'proper' and 'pure'.

We interviewed nine large-scale producers, an even mix of Hausa and Zarma, who had been in the business for between three months and six years. These producers have purchased machines that are connected to Niamey's piped water system. ${ }^{21}$ Treated water comes through the piped network to the homes or shops of the producers and passes through three filters before it enters the machine, which automatically fills half-litre plastic bags with water and seals them. Producers can make approximately thirty sachets per minute with this automated method. Individual sachets are then manually put in larger bags of twenty and sold to boutiques in Niamey or delivered to small shops in surrounding villages. A few sell sachets in bulk to the vendors with pushcarts or to women with refrigerators who send their children out to sell water.

Among the nine large-scale producers we interviewed, five produced sachets in small storage spaces or roadside shops, and four had installed the machines in their homes (Figures 4 and 5). Since work done in the home is not taxed, the latter serves mostly as a means to avoid paying government taxes. Large-scale sachet production is often a family affair, partially as a result of the space of production. Children help run the machines or pack the sachets in larger bags of twenty. In other cases, producers employ and pay others who may or may not be family members. Some owned trucks that they used to deliver sachets in bulk to boutiques and villages. Income from large-scale production varies depending on the number of clients.

Estimating profits for producers is complicated. Producers who sell an average of 1,400 half-litre bags per day - in batches of twenty for 200 CFA francs per batch - earn approximately 14,000 CFA francs gross per day. However, producers have more expenses than vendors. First, large-scale producers have to buy the machines, mostly in Nigeria since they were not yet available in Niger, at a cost of around 1.33 million CFA francs. This does not include the expense involved in travel to and from Nigeria, transporting the machine back to Niamey, and customs fees. This is a considerable amount, especially if one considers that the

\footnotetext{
${ }^{21}$ These machines are about two metres tall, one metre wide, and one metre deep.
} 


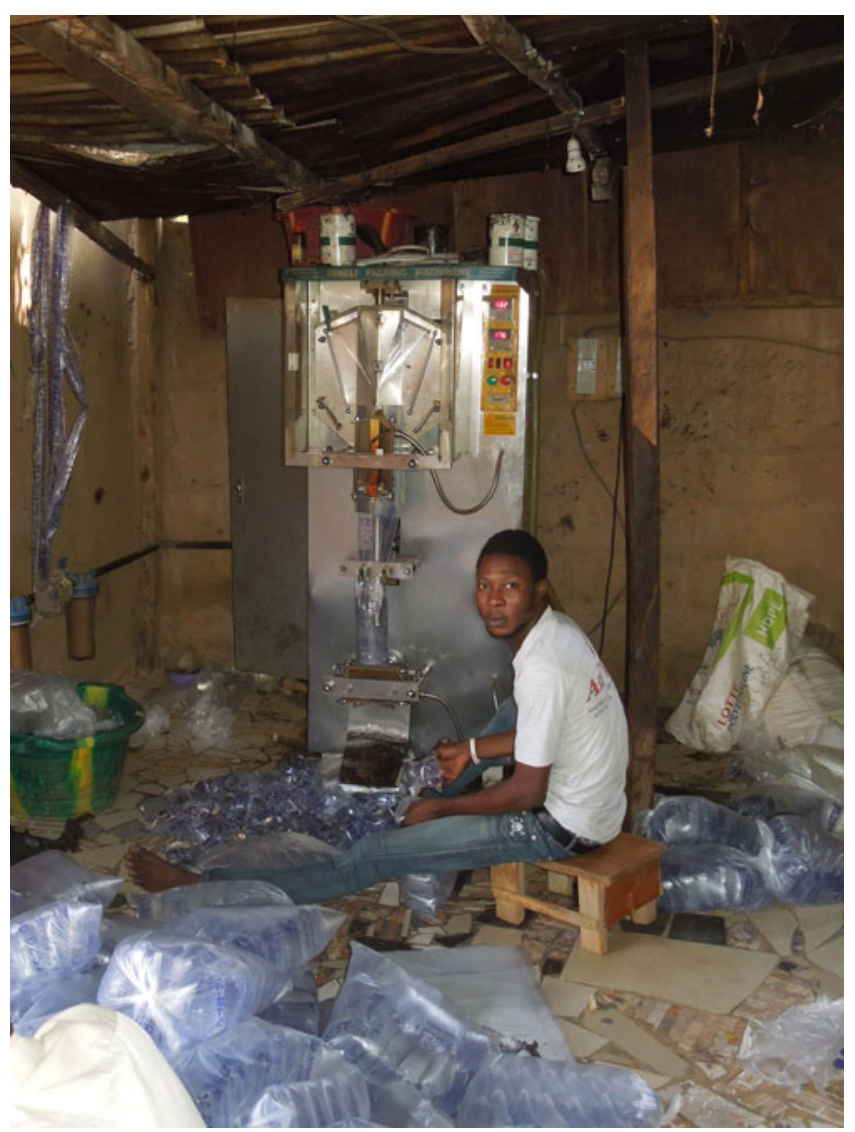

FIGURE 4 Automated sachet-filling machine in a private home.

average Nigerien earns approximately 500 CFA francs per day and the producers are not wealthy. ${ }^{22}$ Furthermore, producers complained that the machines were always breaking down, particularly the ones imported to Nigeria from China, forcing them to pay for repairs and replacement parts. In addition to these upfront costs, the machines are connected to the piped water system, which means paying for the connection and for monthly water use. Electricity is required to run the machines, and a few producers indicated that they had also purchased generators so that they could continue to produce sachets even when the flow of electricity was inconsistent. ${ }^{23}$ Producers also have to buy rolls of plastic bags from the market to use in the machines, and pay any employees they have.

\footnotetext{
${ }^{22}$ One producer stated that it took him three years to pay off the loan to buy his machine.

${ }^{23}$ Generators allow producers to continue production during the hot season, which is when producers reported their largest profits but when the electrical supply to Niamey is least reliable.
} 


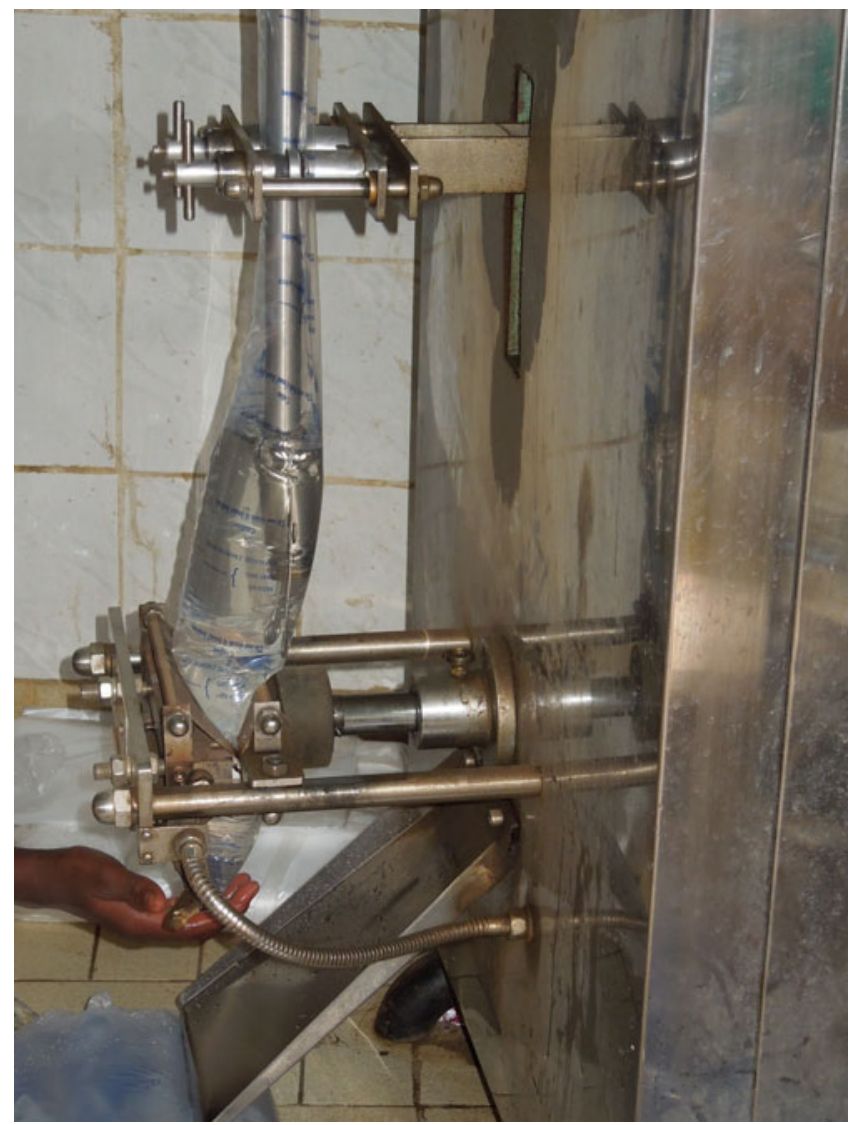

FIGURE 5 Close-up image of the automated process.

Producers expressed varying levels of satisfaction, with all citing some difficulties in their occupation. Two told us that the income was acceptable: were it not so, they would seek other work. Three said that they were actively looking for other jobs because there is little money left over from water sales after paying bills. Other problems included working with unreliable machines, painful hands due to handling cold water for hours at a time, stiff competition, and slow sales volume outside the hot season.

Sachet water producers are key players in the hybridized water economy in Niamey. The machines they use are connected to the piped water network and electrical grid, but the government does not collect taxes on the sachets sold or profits made. These producers also link local vendors to global systems, as the machines they use are made in Nigeria or imported from China to Nigeria, and most (if not all) of the plastic bags are made outside Niger as well. Thus, the landscape backstory of discarded plastic water bags does not end with producers; rather, it continues beyond them and across a multitude of systems of global trade and interdependence. 


\section{Purity: bottles or sachets}

But how pure is 'pure water'? Our research on sachets bears out the findings of Gleick (2010) and others, who question the idea that bottled water - which is less regulated than tap water by national governments - is cleaner and safer than tap water. In theory, the purification and filtration should guarantee that the water is 'pure'. In addition, the mechanical sealing, which indicates industrial production, adds value to the sachet and increases consumer confidence in a way that the hand-tied bags do not, but the sachets remain more affordable than their bottled equivalent. In practice, matters are more complex. Producers are not required to have their filters tested. None of those we observed were wearing gloves, masks or uniforms. We encountered a young man who was working with a bad finger cut, an injury he sustained while using the sachet-sealing machine. Furthermore, consumers have no way of knowing the sources of the water in the sachets. They assume that it comes directly from the piped network. As long as the sachets have printed labels and the water appears clear, consumers typically assume that the water is 'pure'. We could not identify any studies of the purity of 'pure water' in Niger, but tests of 'pure water' in neighbouring Nigeria are alarming because 'the results of most of the studies on sachet water to determine purity and safety have almost always churned up evidence of microbial and in some cases chemical contaminants' (Peter 2012: 2; see also Dada 2009; Ngmekpele and Hawkins 2014; Stoler et al. 2014; Fisher et al. 2015; Ibrahim et al. 2015). One boutiquier in our study suggested with a mixture of cynicism and resignation that there was no point questioning him about the purity of his water. 'This is Africa,' he said. He knows that he cannot guarantee the purity of his piya wata, and he knows of clients who have become ill from consuming it, but he must continue selling it to earn a living. He added that his clients' trust in the purity of sachet water is naive.

In addition, the plastic bags themselves pose health risks. Although consumers of sachet water typically drink the water immediately, producers make and store the bags in garages or homes for days or weeks before they are distributed (Figure 6). Boutiquiers who buy water in bulk may store it for weeks or months in their shops until it sells. Garages, homes and shops all usually lack air conditioning and are subject to sweltering heat during most of the year. The length and conditions of sachet storage can cause the plastic to leach into the water it holds (Hungerford 2012). These concerns do not seem to impede the water sachet business in Niamey, however, which is instead affected by other conditions, such as flow of water, electricity, temperatures (producers and vendors reported reduced profits during the cool season), or Muslims' non-consumption of food and water between sunrise and sunset during the month of Ramadan.

Sachet water and the discarded bags are part of a larger system we refer to as 'global plastic capitalism' (Keough and Youngstedt 2014). This system involves the production and international trade of plastic materials - including water bottles, bags, shoes, kitchenware and toys, among many other items - as well as the perceived and planned obsolescence that maintains and expands the customer base for particular products. Sachet water, like bottled water (Gleick 2010; Hawkins et al. 2015), is linked to the global plastic capitalist system. Like plastic bottles, sachets are made from cheap plastic produced in mass quantities and transformed into products that, when filled with water, suggest to consumers 


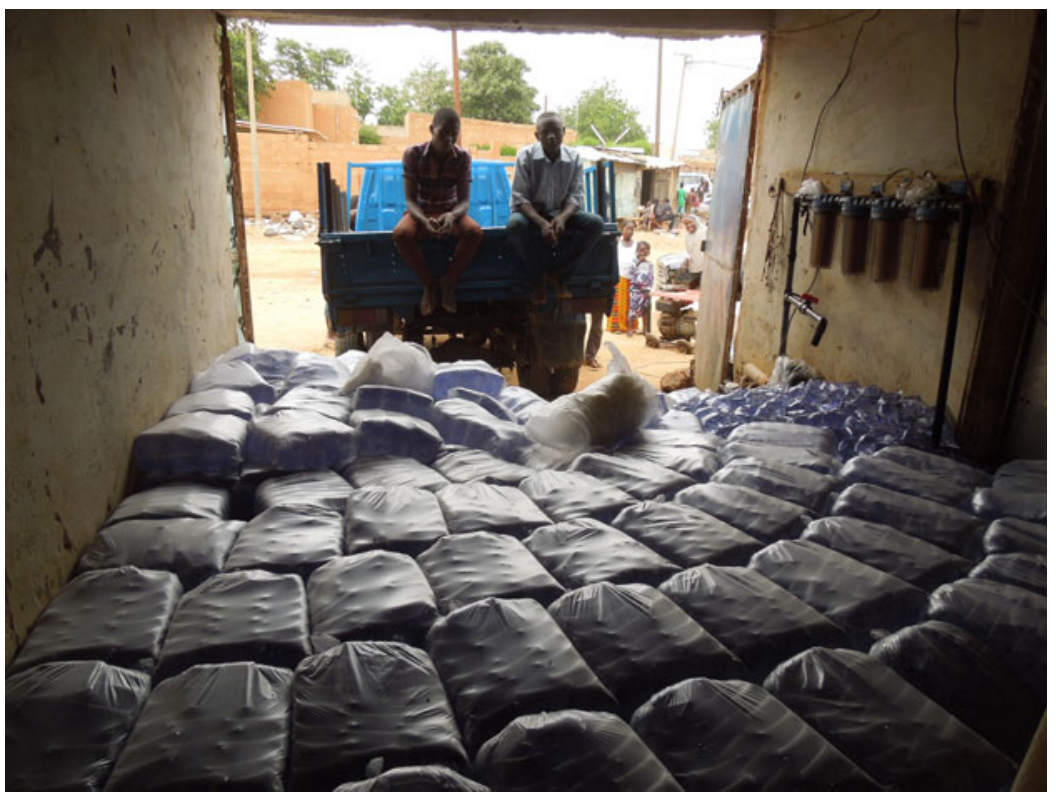

FIGURE 6 Sachet water in bulk (bags of twenty) stored in a garage waiting to be delivered to boutiques in Niamey and the surrounding villages.

that they are drinking clean water. Like bottled water, sachet water emerged as water systems became privatized through neoliberal economic practices, fragmenting the water supply and impacting waste infrastructure (or the environment when such infrastructure is absent, as with Niamey's landscapes of discarded water bags). Bottled and sachet water have some characteristics in common, but they are also different in several ways. The consumption of bottled water is a status symbol, largely because it is very expensive. Most Niaméens have never tasted it. The consumption of sachet water is a symbol of poverty to some, but comes with ideas of entitlement to others. Both bottled water and sachet water are considered forms of 'pure' water by consumers, in part because both forms are mechanically sealed, but, in reality, the former is probably cleaner than the latter. ${ }^{24}$ However, sachet water can be quite clean if the production process is done properly. The biggest difference between the two forms of commercially packaged water, though, is that, in Niamey, the plastic bottles - unlike the sachets - are recycled informally (women in particular use them to store cooking oil and other ingredients). While much has been written on the environmental hazards created by discarded plastic water bottles, it is the sachets that are a bigger waste and drain-clogging problem in Niamey.

\footnotetext{
${ }^{24}$ Bottled water is often mixed into baby food in Niger.
} 


\section{Conclusion: commodification and value}

This article has examined the backstory of sachet water in Niamey - a complex and fluid example of global plastic capitalism in motion. By linking global value chains and commodity chains, this story reveals important dimensions of power, class, gender, age, cultural values and concepts of purity in Niamey. Our examination of global value chains and commodity chains involved tracing discarded sachet water bags on the roadsides of Niamey back to the consumers who dropped them, the vendors who sold them, the producers - using the municipal water supply and electrical grid - who filled them, and the Chinese and Nigerian companies that manufacture and export plastic bags and automated sachet water packing machines. We demonstrated how the importance of labels, temperature of water, time of year and ideas about water purity add both economic and symbolic value to the sachet, typically during the stages of production. Finally, we explained how the sachet water economy simultaneously combines characteristics of several water governance models.

The commodification of water and the backstory of discarded water bags is not complete, however, without careful consideration of the commodity chains and value chains of which it is a part. These chains connect two distinct commodities: water and plastic bags. Each travels through a different commodity chain until the point at which they are mechanically combined. When the plastic bag is filled with (presumably) filtered water and sealed in a labelled bag, a new, more expensive commodity is created, one whose economic value increases further upon refrigeration, especially during the hot season, and whose symbolic value varies with the socio-economic status of the consumer.

It is here that we return to our comparison between sachet water and cash crop value chains that we mentioned earlier. While the value of cash crops is added and subtracted at different stages in the commodity chain, the packaging does little to change the value of the commodity, other than perhaps to protect it in shipping. Sachets, however, markedly increase the value of the water contained within them. Unlike cash crops, which are grown primarily for export out of the continent, sachet water is consumed very close to the place where it is produced - sometimes on the same street - largely due to the fact that water is heavy and expensive to transport. Sachet water is consumed by individuals at all socio-economic levels in Niamey, including the producers and their workers; therefore, there is little 'alienation' along a relatively short commodity chain. Sachet water is linked to the global economy through the one-way flow of manufactured products from China to Africa (Lee 2014), but, unlike cash crops grown in Africa and bound for Europe or North America, the consumer base for sachet water is very much a local one.

The points at which value is added to or subtracted from sachets result in further differences from cash crops. Unlike cash crops, whose value increases continuously from raw material to consumer, the value of sachets and the water in them fluctuates as they move through the commodity chain, and with the time of year. This is in part due to the fact that, unlike agricultural products, water can be stored in sachets for long periods of time, minimizing the risk of investment to producers and vendors, and guaranteeing a consistent supply to consumers.

How might the theories of Tsing, Appadurai and Swyngedouw further illuminate questions of value in the selling of sachet water? Our study supports Tsing's 
assertion (2013) that value is created and assessed at all points in the commodity chain, and that non-capitalist social relations, such as those between refrigeratorowning mothers and their children, change in part due to their involvement in capitalist processes. And if, as Appadurai emphasizes, the process of commodity exchange is key in creating value (1986), in this case sachet water is exchanged twice in the commodity chain: once between producer and vendor, and then again between vendor and customer. Although the vendors pay for the bags, the bag's economic value increases once it is cooled, so processes occurring before the second exchange add value as well. It is the process of production, however, as Swyngedouw suggests (2004), that results in the most significant change in economic value for sachet water. When the two individual commodities are combined to produce piya wata, the economic value of each increases significantly, not only as a product ready for consumption, but also as product that can be stored long term. Furthermore, production itself offers a livelihood for men in a city with high unemployment. The process of chilling water is another phase of production that increases the economic value of the new commodity exponentially. In fact, cold water is so valuable to consumers that they will choose it despite perceptions about its public consumption and cultural associations with cold-related health problems.

Producers, vendors and consumers benefit from the fact that sachets are used to store water. For producers, this allows them to produce a surplus of sachets when water flow through the piped network is consistent, ensuring a continued supply of sachets even when - as during the hot season, when demand for sachet water is also highest - the piped network later proves unreliable. Vendors reported selling more sachets during this season than at any other time of the year, and many vendors purchased extra bulk packs of sachets in preparation for this. Of course, the fluctuating electrical supply during the hot season presents challenges for refrigeration. To consumers, the availability of cold water is even more valuable during the hot season, when daytime temperatures reach $45^{\circ} \mathrm{C}$ or higher and both formal and hybrid systems of water delivery are inhibited by reduced water flow.

While water sachets are part of larger, formal trade flows, they are also integrated into Niamey's 'community economy' (Bakker 2010) - the sector that employs most of the city's population (Youngstedt 2013). In Niamey, the sachet water economy has remained largely unregulated by the state or private entities. There are indirect controls, such as the price of water obtained through the piped network and the charge for electricity, that are set by the government or public-private partnerships, but the distribution and sale of sachets remain under the control of producers and vendors, and these actors standardize the price (both for individual sale or in bulk) of sachets throughout the city.

The sale of sachet water moves between government, corporate and community economic systems, a condition accounted for in Bakker's (2010) typology of the urban water supply. Bakker locates water vendors in vague water service areas between those under corporate control and those entirely outside both corporate and government control. Large-scale producers of water sachets are connected to water and electrical distribution systems, both of which are controlled by publicprivate partnerships, but many producers do not pay taxes on the sachets sold because their production occurs in their homes. Furthermore, the producers in this story have privatized part of Niamey's water industry, both in their role as individual entrepreneurs and in the sense that many produce sachet water in the privacy 
of their home. However, when sachets are sold from roadside boutiques, it is boutiquiers (rather than producers) who must pay taxes on the sachets, and on all other goods they sell from their stores. The mobile vendors and their mothers and grandmothers, on the other hand, pay no taxes on the income they collect. Furthermore, producers and vendors alike benefit from informal social networks of regular customers, which, Tsing (2013) asserts, exist when alienation between worker and commodity is minimized. The social networks among producers, vendors and consumers are, according to our informants, vital for business, just as these social networks advantage those in other informal economies in Africa (Meagher 2010). Thus, the sachet water economy is a quintessential example of Bakker's (2010) 'hybrid' economy because it combines elements of all three governance models: public/government, private corporations and community organizations. It exists because of direct access to the piped water and electrical networks, which are functions of public-private partnerships, it serves community needs (the desire for both cold water and employment) and it involves social networks for efficient functioning, but there is no cooperative community governance of the system, despite the fact that the price of a cold sachet is fixed throughout the city.

All in all, the political economy of 'pure water' produces an extensive commodity and value chain through which the bags pass. These exchanges are embedded in cultural contexts, as there are commonly held norms about who can sell water in public spaces, and changing concerns about consuming cold products. The age-based and gendered division of labour within the process, the cultural perceptions placed on the consumption of sachet water, the social networks involved in the production and distribution of 'pure water', the hybridized state in which the 'pure water' system is positioned and the global conditions that impact on local realities are all part of the backstory of discarded plastic water bags. These are essential elements in the biographies of objects discarded on the roadsides of Niamey.

\section{Acknowledgements}

We would like to thank our Nigerien field assistants, Cheiffou Idrissa and Koche 'Yaji' Dan Jima, for their help with this project, and all the consumers, vendors and producers who gave us their time. We appreciate the valuable comments from our reviewers, which greatly improved the quality of our manuscript. Funding and support for this work were provided by the American Geographical Society, the Ruth and Ted Braun Foundation, the Fulbright Foundation and Saginaw Valley State University.

\section{References}

Appadurai, A. (ed.) (1986) The Social Life of Things: commodities in cultural perspective. Cambridge: Cambridge University Press.

Bakker, K. (2010) Privatizing Water: governance failure and the world's urban water crisis. Ithaca NY: Cornell University Press.

Bardasi, E. and Q. Wodon (2008) 'Who pays the most for water? Alternative providers and service cost in Niger', Economics Bulletin 9 (20): 1-10.

Bontianti, A., H. Hungerford, H. Younsa and A. Noma (2014) 'Fluid experiences: comparing local adaptations to water inaccessibility in two disadvantaged neighborhoods in Niamey, Niger', Habitat International 43: 283-92. 
Bridge, G. and A. Smith (2003) 'Intimate encounters: economy - culture - commodity', Environment and Planning D: Space and Society 21: 257-68.

Bulchi, V. (2002) 'Introduction' in V. Bulchi (ed.), The Material Culture Reader. Oxford: Berg.

Callaway, B. J. (1984) 'Ambiguous consequences of the socialisation and seclusion of Hausa women', Journal of Modern African Studies 22 (3): 429-50.

Cook, I. et al. (2004) 'Follow the thing: papaya', Antipode 36 (4): 642-64.

Coombe, R. (1996) 'Embodied trademarks: mimesis and alterity on American cultural frontiers', Cultural Anthropology 11 (2): 202-25.

Dada, A. C. (2009) 'Sachet water phenomenon in Nigeria: assessment of the potential health impacts', African Journal of Microbiology Research 3 (1): 15-21.

Fisher, M. B., A. R. Williams, M. F. Jalloh, G. Saquee, R. E. S. Bain and J. K. Bartram (2015) 'Microbiological and chemical quality of packaged sachet water and household stored drinking water in Freetown, Sierra Leone', PLoS ONE 10 (7): e0131772.

Gibbon, P. and S. Ponte (2005) Trading Down: Africa, value chains, and the global economy. Philadelphia PA: Temple University Press.

Gleick, P. (2010) Bottled and Sold: the story behind our obsession with bottled water. Washington DC: Island Press.

Hawkins, G., E. Potter and K. Race (2015) Plastic Water: the social and material life of bottled water. Cambridge MA: MIT Press.

Hill, P. (1969) 'Hidden trade in Hausaland', Man 4 (3): 392-409.

Humphrey, J. and H. Schmitz (2002) 'Developing country firms in the world economy: governance and upgrading in global value chains'. INEF Report 61. Duisburg: Institut für Entwicklung und Frieden der Gerhard-MercatorUniversität Duisburg (INEF) <http://citeseerx.ist.psu.edu/viewdoc/download? doi=10.1.1.557.1063\&rep=rep1\&type $=$ pdf $>$, accessed 16 October 2017.

Hungerford, H. (2012) 'Water, cities, bodies: a relational understanding of Niamey, Niger'. PhD thesis, University of Kansas.

Ibrahim, M., M. Umaru and A. Akinsoji (2015) 'Qualitative assessment of sachet and bottled water marketed in Bauchi Metropolis, Nigeria', Journal of Food Process Engineering 37: 11-23.

Kaplinsky, R. (2000) 'Globalisation and unequalisation: what can be learned from value chain analysis?', Journal of Development Studies 37 (2): 117-46.

Kaplinsky, R. and M. Morris (2001) 'A handbook for value chain research'. Ottawa: International Development Research Centre (IDRC) < https://www.ids.ac.uk/ids/ global/pdfs/ValuechainHBRKMMNov2001.pdf>, accessed 26 July 2016.

Keough, S. and S. Youngstedt (2014) 'The material culture of water: transportation, storage, and consumption in Niamey, Niger', Focus on Geography 57 (4): 152-63.

Kooy, M. and K. Bakker (2014) '(Post) colonial pipes: urban water supply in colonial and contemporary Jakarta' in F. Colombijin and J. Coté (eds), Cards, Conduits, and Kampongs: the modernization of the Indonesian city, 1920-1960. Leiden: Brill.

Lee, M. (2014) Africa's World Trade: informal economies and globalization from below. London: Zed Books.

Macdonald, K. (2007) 'Globalising justice within coffee supply chains? Fair trade, Starbucks and the transformation of supply chain governance', Third World Quarterly 28 (4): 793-812. 
Meagher, K. (2010) Identity Economics: social networks and the informal economy in Nigeria. Rochester NY: James Currey.

Ngmekpele, B. S. and J. Hawkins (2014) 'Consumers' perception of quality and health benefits of sachet drinking water: evidence from Obuasi in the Ashanti region of Ghana', Developing Country Studies 4 (17): 66-77.

Olivier de Sardan, J.-P. (1982) Concepts et conceptions songhay-zarma. Paris: Nubia.

Orlove, B. and S. C. Caton (2010) 'Water sustainability: anthropological approaches and prospects', Annual Review of Anthropology 39: 401-15.

Page, B. (2005) 'Paying for water and the geography of commodities', Transactions of the Institute of British Geographers 30 (3): 293-306.

Peter, N. (2012) 'How pure is our “pure water'?', Ezine Articles, 16 November $<$ http://ezinearticles.com/?How-Pure-Is-Our-Pure-Water?\&id=7382860>, accessed 16 October 2017.

Ricketts, K., C. Turvey and M. Gómez (2014) 'Value chain approaches to development: smallholder farmer perceptions of risk and benefits across three cocoa chains in Ghana', Journal of Agribusiness in Developing and Emerging Economies 4 (1): 2-22.

Schildkrout, E. (1982) 'Dependency and autonomy: the economic activities of secluded Hausa women in Kano' in E. G. Bay (ed.), Women and Work in Africa. Boulder CO: Westview Press.

Stoler, J., J. Weeks and G. Fink (2012) 'Sachet drinking water in Ghana's AccraTema metropolitan area: past, present, and future', Journal of Water Sanitation Hygiene Development 2 (4): 1-24.

Stoler, J., R. A. Tutu, H. Ahmed, L. A. Frimpong and M. Bello (2014) 'Sachet water quality and brand reputation in two low-income urban communities in Greater Accra, Ghana', American Journal of Tropical Medicine 90 (2): 272-8.

Stoller, P. (2002) Money Has No Smell: the Africanization of New York City. Chicago IL: University of Chicago Press.

Stoller, P. and C. Olkes (1987) In Sorcery's Shadow: a memoir of apprenticeship among the Songhay of Niger. Chicago IL: University of Chicago Press.

Swyngedouw, E. (2004) Social Power and the Urbanization of Water: flows of power. Oxford: Oxford University Press.

Tsing, A. (2013) 'Sorting out commodities: how capitalist value is made through gifts', HAU: Journal of Ethnographic Theory 3 (1): 21-43.

Wagner, J. (2013) 'Introduction' in J. Wagner (ed.), The Social Life of Water. New York NY: Berghahn Books.

Wall, L. L. (1988) Hausa Medicine: illness and well-being in a West African culture. Durham NC: Duke University Press.

Youngstedt, S. M. (2013) Surviving with Dignity: Hausa communities of Niamey, Niger. Lanham MD: Lexington Books.

Youngstedt, S., S. Keough and C. Idrissa (2016) 'Water vendors in Niamey: considering the economic and symbolic nature of water', African Studies Quarterly 16 (2): $27-46$.

Zylberberg, E. (2013) 'Bloom or bust? A global value chain approach to smallholder flower production in Kenya', Journal of Agribusiness in Developing and Emerging Economies 3 (1): 4-26. 


\begin{abstract}
This article examines the commodity chain and value chain of half-litre water bags (referred to as 'pure water' or 'sachet water') in Niamey, Niger. We begin with a focus on the discarded bag and work backwards through the commodity chain to consumers, vendors and finally producers of 'pure water' to reveal the underlying power structures, cultural perceptions and assumptions that ultimately resulted in the discarded bag and landscapes of waste. We assert that the economic value of the plastic bag, largely assigned during the stages of its production, is based on four characteristics: the label, the temperature of the water, the time of year it is sold, and the apparent 'purity' of the water. We further demonstrate how characteristics of economic value are steeped in cultural perceptions and social relationships in Niamey. Using interviews with agents and actors at all levels of the commodity chain, we reveal how this local, hybrid system is connected to and affected by larger, global economic and political forces.
\end{abstract}

\title{
Résumé
}

Cet article examine la chaîne de produits de base et la chaîne de valeur des sacs d'eau (appelée " eau pure » ou " eau en sachet ») de 50cl à Niamey (Niger). Les auteurs commencent par s'intéresser au sac usagé avant de remonter la chaîne des produits de base jusqu'aux consommateurs, puis aux fournisseurs et enfin aux fabricants d' " eau pure » pour révéler les structures de pouvoir, les perceptions culturelles et les prémisses sous-jacents qui aboutissent au sac usagé et aux paysages de déchets. Les auteurs arguent que la valeur économique du sac plastique, essentiellement attribuée au cours des étapes de sa fabrication, repose sur quatre caractéristiques : l'étiquette, la température de l'eau, la période de l'année où l'eau est vendue et la "pureté » apparente de l'eau. Ils démontrent par ailleurs comment ces caractéristiques de valeur économique sont enracinées dans les perceptions culturelles et les rapports sociaux à Niamey. À partir d'entretiens avec des agents et des acteurs à tous les niveaux de la chaîne des produits de base, les auteurs révèlent comment ce système hybride local est lié à, et affecté par, des forces politiques et économiques globales plus importantes. 